\title{
Pengembangan Notifikasi Email Untuk Keamanan Port Menggunakan Metode Port Knocking
}

\author{
Marina Apriani ${ }^{1}$, Arif Harbani ${ }^{2}$ \\ Program Studi Tenik Informatika \\ STIKOM Binaniaga Bogor. \\ Email: arifharbani@gmail.com
}

\begin{abstract}
Port Knocking is a method that is used to close all access to a particular port and a client can access the port when it has successfully performed a series of port beats to several ports that have been set up as trigger ports. This is a problem when the client is not entitled to remote access to the proxy port and is vulnerable to attacks from outside who want to retrieve information from the proxy. Port security on proxy with the port knocking method with the technique of hiding ports is a solution to secure ports from clients that are not allowed to do remote access.

The method used includes four stages of work, namely analysis, design, implementation, and testing. The analysis phase is done by observing the problems in the agency and the needs in the implementation process. The design phase is mapping the scope topology in the implementation process. The implementation phase is carried out by performing several work procedures and the testing phase is carried out to carry out several testing procedures so that conclusions arise. Development of port knocking is done by adding email notifications to the router. The addition of notifications aims to provide an early warning to the administrator when there is a client that successfully accesses one of the ports used as a remote access point.
\end{abstract}

Keywords: port knocking, email notification, port trigger, remote access, mikrotik.

\begin{abstract}
ABSTRAK
Port Knocking merupakan suatu metode yang digunakan untuk menutup seluruh akses pada port tertentu dan seorang client dapat melakukan akses pada port tersebut ketika telah berhasil melakukan serangkaian ketukan port kepada beberapa port yang telah diatur sebagai port pemicu. Hal itu menjadi masalah ketika clent yang tidak berhak melakukan remote access ke port mikrotik dan rentan terhadap serangan dari luar yang ingin mengambil informasi dari mikrotik. Keamanan port pada mikrotik dengan metode port knocking dengan teknik menyembunyikan port adalah solusi untuk mengamankan port dari client yang tidak diizinkan untuk melakukan remote access.

Metode yang digunakan meliputi empat tahap pengerjaan, yaitu analisis, perancangan, implementasi, dan pengujian. Tahap analisis dilakukan pengamatan masalah pada instansi dan kebutuhan dalam proses implementasi. Tahap perancangan dilakukan pemetaan terhadap topologi ruang lingkup dalam proses pengerjaan implementasi. Tahap implementasi dilakukan dengan melakukan beberapa prosedur pengerjaan dan tahap pengujian dilakukan untuk melakukan beberapa prosedur pengujian sehingga memunculkan simpulan.

Pengembangan pada port knocking dilakukan dengan menambahkan notifikasi email pada router. Penambahan notifikasi bertujuan untuk memberikan peringatan dini kepada administrator ketika terdapat client yang berhasil melakukan akses pada salah satu port yang digunakan sebagai jalur remote access.
\end{abstract}

Kata Kunci: port knocking, email notification, port trigger, remote access, mikrotik 


\section{PENDAHULUAN}

Router adalah perangkat keras jaringan komputer yang menghubungkan beberapa jaringan yang sama atau berbeda dan juga sebagai alat untuk mengatur keluar dan masuknya suatu data pada jaringan, router berada pada lapisan terluar yang terhubung langsung ke jaringan publik. Router sering menjadi salah satu target penyerang untuk tujuan mengambil informasi data yang melalui router. Hal ini mengakibatkan keamanan router rentan terhadap serangan dari luar maupun dalam. Selain itu administrator tidak bisa secara terus menerus memantau router yang berada di ruang NOC tempat router mikrotik di letakkan.

Permasalahan ini yang mengharuskan pihak administrator jaringan untuk membuat keamanan router khususnya router mikrotik dengan menutup port mikrotik. Port yang terbuka akan mempermudah penyerang mengetahui port-port yang mudah diakses dengan menggunakan aplikasi tool scanner seperti NMAP-Zenmap, MiTec Network Scanner, SoftPerfect Network Scanner, Network DeepScan, Network Scanner dan lain-lain. Solusi dari masalah tersebut diperlukan suatu keamanan pada router mikrotik agar port-port yang terbuka dapat tertutup sehingga sulit diketahui penyerang bahwa port tersebut tertutup. Metode yang digunakan adalah port knocking. Port knocking adalah teknik yang dilakukan untuk membuka akses ke port tertentu yang telah diblok oleh firewall pada perangkat jaringan dengan cara mengirimkan paket atau koneksi tertentu. Koneksi bisa berupa protokol TCP, UDP maupun ICMP.

Selain itu untuk mempermudah administrator jaringan dalam memantau router yaitu dengan mengirimkan notifikasi langsung ke administrator jaringan apabila ada serangan pada router mikrotik. Notifikasi yang digunakan merupakan notifikasi email.

Rumusan masalah dalam penelitian ini adalah:

1. Bagaimana pengaruh notifikasi email terhadap proses autentikasi Port Knocking

2. Bagaimana menerapkan keamanan port dengan menggunakan metode port knocking dengan notifikasi email ?

Adapun tujuan penelitian ini dimaksudkan untuk:

1. Menjaga keamanan port menggunakan metode port knocking.

2. Membatasi penggunaan remote access dari client yang yang tidak mempunyai hak untuk melakukan remote access dan router dapat melakukan pengiriman notifikasi email yang terkirim langsung kepada pihak administrator ketika terdeteksi adanya serangan

\section{METODE}

Metode yang digunakan dalam pembuatan Keamanan Port pada Mikrotik dengan Metode Port Knocking terdiri dari 4 tahapan. Metode dapat dilihat pada Gambar 1.

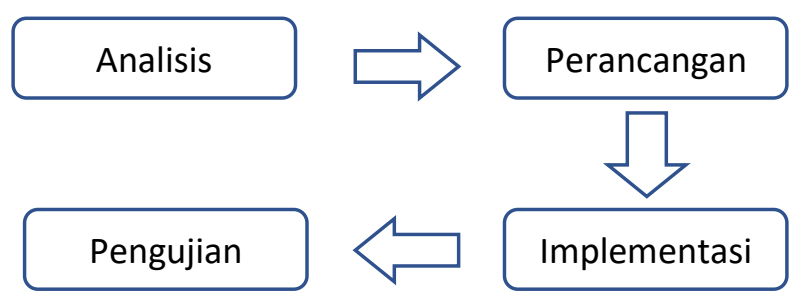

Gambar 1 Metode pengerjaan 


\section{Fase Analisis}

Tahap ini merupakan langkah pemahaman sistem, identifikasi masalah dan kebutuhan sehingga dapat menganalisis rancangan pembuatan sesuai dengan kebutuhan yang ada.

\section{Analisis masalah}

Masalah yang dihadapi adalah banyaknya pengguna perangkat mikrotik yang harus diatur dan dikelola. Banyaknya username dan password yang digunakan membuat keamanan mikrotik menjadi rentan akan serangan karena penyerangan jenis brute force mencoba semua kombinasi username dan password.

\section{Analisis kebutuhan}

Dalam pembuatan keamanan port pada mikrotik dengan port knocking dibutuhkan perangkat keras dan perangkat lunak yang merujuk ke Tabel 1 .

Tabel 1 Daftar kebutuhan perangkat keras dan perangkat lunak

\begin{tabular}{|l|l|l|c|}
\hline \multicolumn{1}{|c|}{ Perangkat keras } & \multicolumn{1}{|c|}{ Spesifikasi } & \multicolumn{1}{c|}{ Perangkat lunak } & Spesifikasi \\
\hline Mikrotik router & Mikrotik RB951UI-2ND & Winbox & Winbox v3.10 \\
\hline Kabel UTP & Kabel Straight & Google Chrome & \\
\hline Laptop & Laptop HP Notebook & Putty & \\
\hline RAM & 4 GB & & \\
\hline
\end{tabular}

\section{Fase Perancangan}

Perancangan dilakukan menggunakan jaringan yang sudah ada untuk mengkonfigurasi jaringan mikrotik. Tahap perancangan ini bertujuan untuk memberikan gambaran tentang topologi jaringan sesuai dengan kebutuhan. Topologi yang digunakan hanya mengambil sebagian dari topologi dalam skala laboratorium terlihat pada gambar digunakan hanya yang berada dalam kotak. Topologi jaringan yang dibuat seperti ditunjukkan pada Gambar 2. Sedangkan untuk daftar pengalamatan IP pada topologi jaringan merujuk pada Tabel 2 .

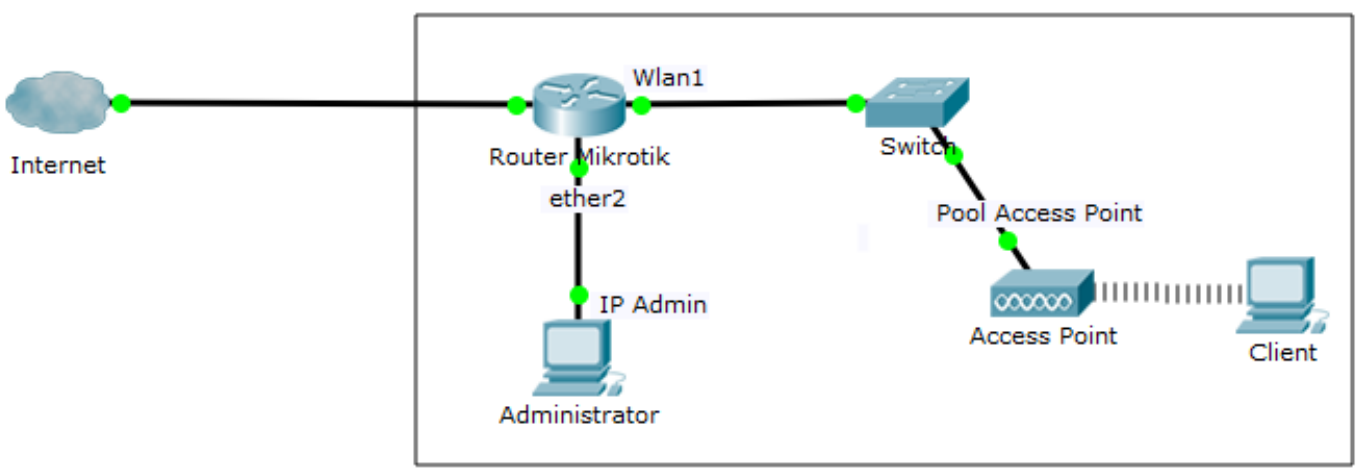

Gambar 2. Topologi jaringan

Tabel 2 Daftar pengalamatan IP pada topologi jaringan

\begin{tabular}{|l|l|}
\hline \multicolumn{1}{|c|}{ Titik } & \multicolumn{1}{c|}{ IP } \\
\hline Ether2 & $192.168 .88 .1 / 24$ \\
\hline Wlan1 & $10.10 .10 .1 / 24$ \\
\hline IP Admin & $192.168 .88 .2 / 24$ \\
\hline Pool Access Point & $10.10 .10 .0 / 24$ \\
\hline
\end{tabular}




\section{Fase Implementasi}

\section{Konfigurasi IP Address}

Pemberian IP dilakukan pada interface ether2 dengan alamat 192.168.88.1/24 yang digunakan untuk menghubungkan admin jaringan dengan mikrotik. Selain pemberian IP pada ether2, Pemberian IP juga dilakukan pada interface wlan1 dengan alamat 10.10.10.1/24. Pemberian alamat pada wlan1 digunakan sebagai alamat access point.

\section{Konfigurasi Access Point}

Pembuatan access point wireless pada mode access point bridge dengan pemberian nama ssid yaitu wifi. Pembuatan wireless tersebut dilanjutkan dengan pembuatan IP pool yang mengarah ke IP address interface wlan1 yang sudah dikonfigurasi. Pembuatan IP pool ini bertujuan agar memberikan range IP yang akan didapatkan oleh client ketika mengaktifkan atau menggunakan access point yang telah dibuat. Pembuatan range IP dari 10.10.10.2 sampai dengan 10.10.10.254 yang diberi nama pool1. Pembuatan IP DHCP server berfungsi sebagai pemberi IP kepada client yang melakukan permintaan IP kepada interface yang telah ditunjuk sebagai DHCP server. Interface yang akan digunakan sebagai dhcp-server adalah wlan1 dan pemberian IP diberikan dengan list IP yang sudah dikonfigurasi pada pool. Penambahan IP gateway dari mikrotik bertujuan untuk mengetahui IP mikrotik ketika client menggunakan access point dengan network address 10.10.10.0/24.

\section{Konfigurasi Firewall Filter Rules}

Konfigurasi utama dalam pembuatan keamanan port dengan metode port knocking adalah konfigurasi firewall filter rule pada mikrotik. Firewall filter rule bertujuan sebagai pengatur data yang masuk ataupun yang keluar melalui router sehingga router dapat membuat aturan untuk setiap data apakah data tersebut diterima, diteruskan ataupun dibuang. Pada konfigurasi port knocking, penggunaan firewall filter rule digunakan untuk menutup semua akses yang masuk pada port remote access seperti SSH, telnet, winbox, ataupun web config (webfig). Web config merupakan sebuah utility pada mikrotik yang digunakan untuk melakukan konfigurasi router dengan web browser.

Sebelum melakukan firewall filter rules, default port yang digunakan pada setiap jenis remote access dialihkan pada port baru. Hal tersebut dilakukan untuk meningkatkan keamanan setiap port sehingga ketika ada seseorang yang ingin melakukan remote access dengan tujuan port default, maka akses tidak akan bisa dilakukan. Perubahan setiap port akses merujuk pada Tabel 3.

Tabel 3 Perubahan port akses

\begin{tabular}{|c|c|c|}
\hline Jenis Akses & Port default & Port baru \\
\hline SSH & 22 & 2224 \\
\hline Telnet & 23 & 2322 \\
\hline Webfig & 80 & 8020 \\
\hline Winbox & 8291 & 8280 \\
\hline
\end{tabular}

Ketika semua port telah dialihkan pada port baru, dibuat sebuah konfigurasi pada firewall filter rule untuk memberikan akses izin kepada administrator menuju router tanpa harus menggunakan metode port knocking. Dalam rule tersebut, administrator menggunakan IP statik dengan alamat 192.168.88.2/24. Konfigurasi tersebut seperti ditunjukkan pada Gambar 3. 


\section{;; ADMIN IP STATIC}

ip firewall filter add chain=input action=accept protocol=tcp src-address=192.168.88.2 dstaddress $=192.168 .88 .1$ dst-port $=8020,2224,2322,8280$

Gambar 3. Pembuatan firewall filter rule untuk administrator

Pembuatan port knocking rule pada mikrotik untuk port yang digunakan sebagai remote access. Pembuatan rules tersebut bertujuan untuk menutup semua akses pada port yang digunakan sebagai remote access dan hanya akan bisa dibuka jika seorang client mampu melakukan knocking port secara berurut.

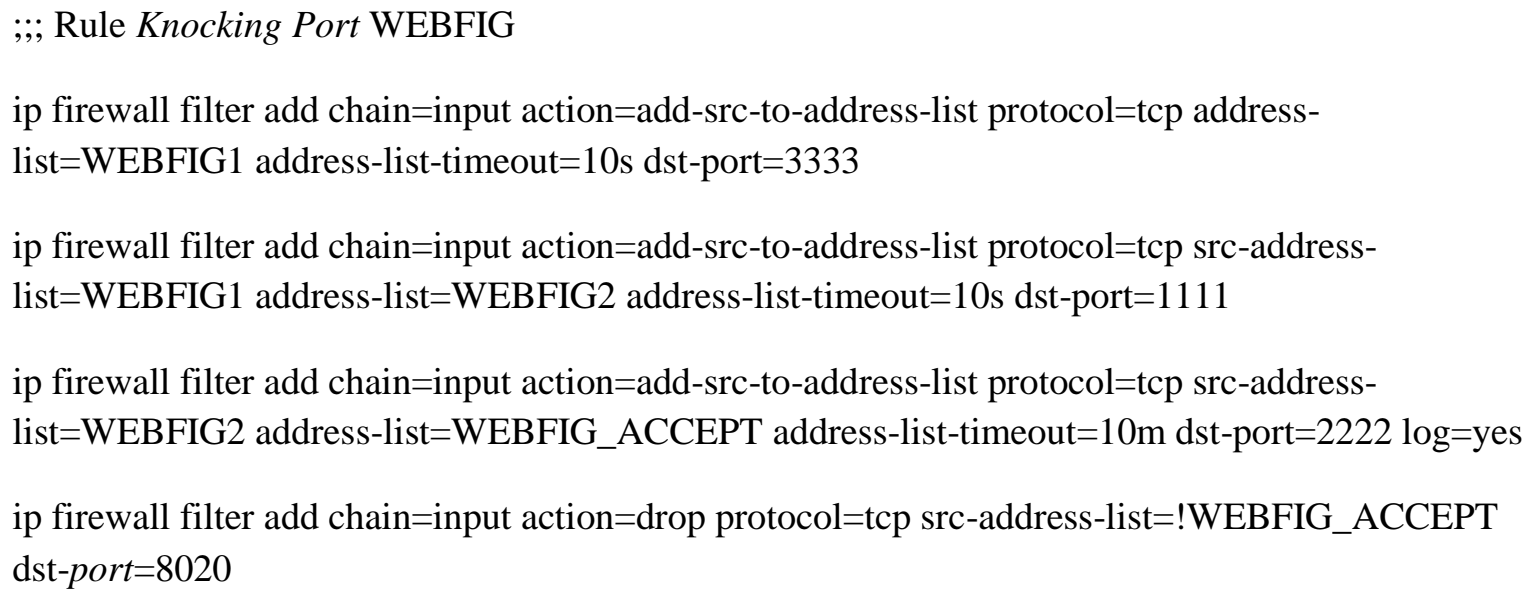

Gambar 4. Pembuatan firewall filter rule port webfig

Gambar 4 menunjukkan bahwa pembuatan rule knocking untuk port webfig. Baris pertama menunjukan perintah bahwa port pemicu sebagai port palsu awal yang digunakan adalah port 1111, port pemicu selanjutnya 2222, dan port pemicu terakhir untuk dapat menuju ke port webfig adalah 3333. Ketika berhasil melalui semua port pemicu yang ada, maka untuk masuk ke port webfig hanya lakukan request port webfig yang sudah dialihkan. Peningkatan keamanan port dilakukan pada efisiensi waktu yang digunakan. Batas waktu yang melebihi saat melakukan request port pemicu maka permintaan tidak akan berhasil dan diulang. Hal ini berlaku juga untuk port mikrotik yang lain namun dengan port pemicu yang berbeda tiap pintunya, misalnya Telnet, SSH dan Winbox. Port pemicu yang digunakan dalam pembuatan port knocking merujuk pada tabel 4 .

Tabel 4 Daftar port pemicu pembuatan port knocking

\begin{tabular}{|l|l|l|l|l|}
\hline \multicolumn{1}{|c|}{ Jenis Akses } & \multicolumn{1}{c|}{ Port pemicu 1 } & Port pemicu 2 & Port pemicu 3 & Port baru \\
\hline SSH & 4444 & 6060 & 5555 & 2224 \\
\hline Telnet & 1234 & 5678 & 1298 & 2322 \\
\hline Webfig & 3333 & 1111 & 2222 & 8020 \\
\hline Winbox & 1122 & 5566 & 3344 & 8280 \\
\hline
\end{tabular}




\section{Fase Pengujian}

\section{Pengujian port scanning}

Pengujian ini dilakukan dengan menggunakan salah satu aplikasi tool scanner yaitu Zenmap. Hal ini dilakukan untuk mengetahui kondisi port mikrotik sebelum dan sesudah pemasangan port knocking. IP address dari interface ether2 yaitu 192.168.88.1 dimasukan kedalam tool box target pada Zenmap. IP tersebut akan dilakukan scanning pada port mikrotik. Hasilnya menunjukan pada Gambar 5 status atau kondisi semua port mikrotik dalam keadaan terbuka karena mikrotik belum dilakukan pemasangan port knocking.

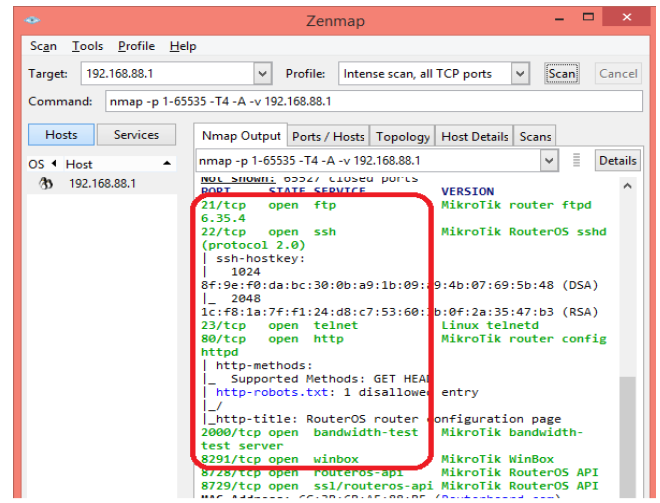

Gambar 5. Scanning port sebelum pemasangan port knocking

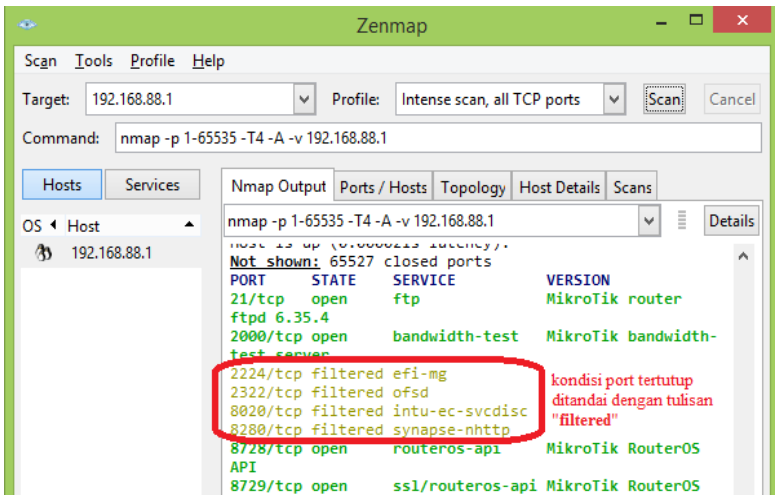

Gambar 6. Scanning port sesudah pemasangan port knocking

Namun sebaliknya pada Gambar 6 menunjukan kondisi semua port mikrotik dalam keadaan tertutup dengan tulisan "filtered" dan nama dari port mikrotik tersebut tidak dapat dikenali. Hal tersebut dikarenakan sebelumnya port default mikrotik sudah dialihkan ke port baru. Kondisi semua port dalam keadaan tertutup karena sudah dilakukan pemasangan port knocking pada router mikrotik.

\section{Akses router dengan alamat admin}

Pengujian ini dilakukan dengan menggunakan alamat admin. Admin bisa langsung masuk ke port mikrotik yang dituju tanpa melakukan knocking port. Gambar 7 menunjukkan bahwa admin bisa langsung masuk ke port webfig tanpa melakukan knocking atau tanpa membuka port pemicu terlebih dahulu hanya dengan membuka port webfig yang sudah dialihkan.

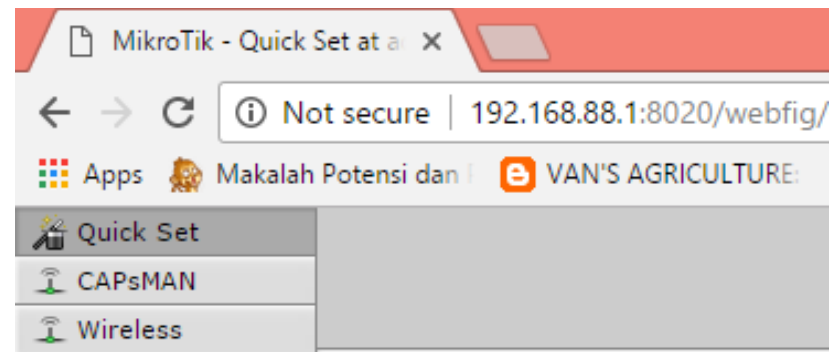

Gambar 7. Admin membuka webfig

\section{Pengujian client akses tanpa melakukan knocking}

Pengujian ini dilakukan dengan client yang melakukan koneksi ke access point yang sudah dibuat. Dengan cara seperti itu, client dapat melakukan koneksi mikrotik menggunakan IP gateway dari access point. Pengujian ini dilakukan dengan cara client melakukan akses mikrotik tanpa melakukan knocking ke port pemicu. Gambar 8 menunjukkan bahwa pada awal gambar client tidak bisa 
membuka port winbox tersebut dengan menggunakan port default. Sedangkan gambar yang berada di sebelahnya menunjukkan bahwa meskipun client mengetahui port winbox yang telah dialihkan dari port default, namun tetap client tidak berhasil membuka port winbox. Hal ini disebabkan client tidak melakukan knocking port ke port pemicu sehingga akses pun tidak bisa dilakukan.
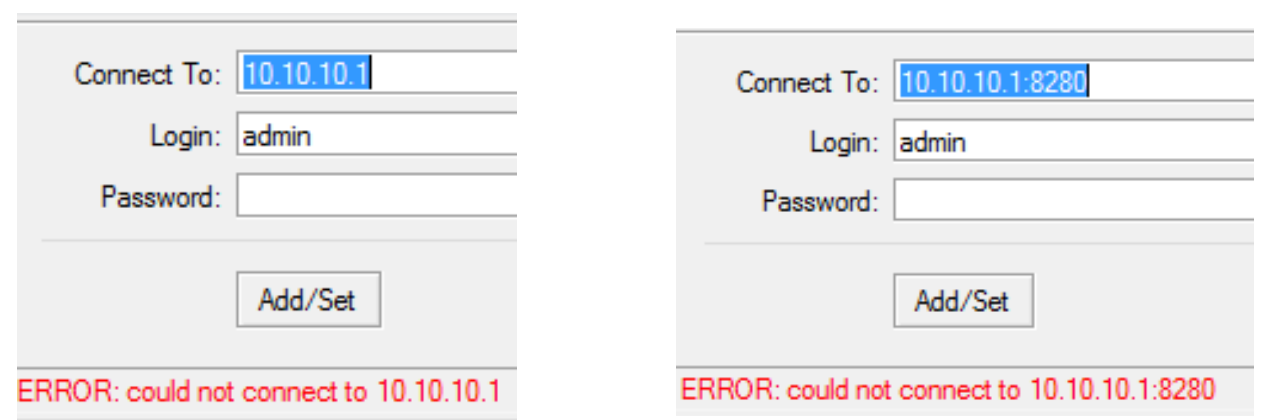

Gambar 8. Client gagal masuk port winbox

\section{Pengujian client akses dengan melakukan knocking}

Pengujian ini dilakukan dengan client yang melakukan knocking ke port pemicu terlebih dahulu lalu masuk ke port SSH yang sudah dialihkan dari port default. Gambar 9 menunjukkan bahwa client berhasil membuka port SSH dengan melakukan knocking ke port pemicu yang telah dibuat untuk port SSH. Namun seperti penjelasan sebelumnya bahwa untuk menambah keamanan mikrotik dilakukan pembatasan waktu akses yang telah dibuat pada firewall filter rule. Ketika batas waktu yang ditentukan telah habis maka client tidak dapat melakukan akses ke port SSH, melainkan harus melakukan knocking port ke port pemicu lagi terlebih dahulu.

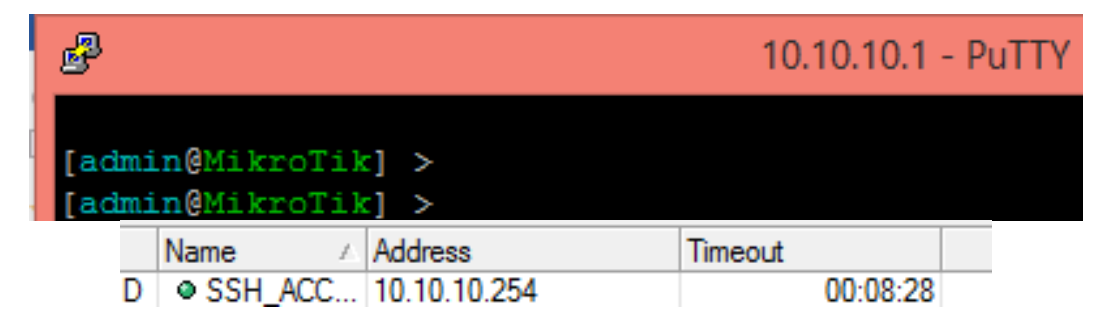

Gambar 9. Client Berhasil masuk dengan knocking

\section{HASIL DAN PEMBAHASAN}

\section{METODE PENGEMBANGAN}

\section{Fase Perancangan}

Untuk menerapkan notifikasi email maka dibuat penerapan topologi. Gambar 2 memperlihatkan topologi yang akan dibangun untuk implementasi port knocking dengan notifikasi email. Topologi pada pengembangan ini menggunakan akses internet untuk masuk ke dalam email. Pemberian IP address untuk topologi dibawah merujuk pada Tabel 2.

\section{Fase Implementasi}

Pada tahap ini dilakukan konfigurasi pada routerboard mikrotik RB951 menggunakan perangkat lunak WinBox. Pada tahap pertama yaitu melakukan beberapa langkah konfigurasi pada mikrotik agar 
dapat melakukan akses internet. Sumber internet yang digunakan berasal dari tethering handphone menggunakan USB pada mikrotik. Pada saat tethering diaktifkan, mikrotik akan membaca interface LTE seperti yang ditunjukkan pada Gambar 10.

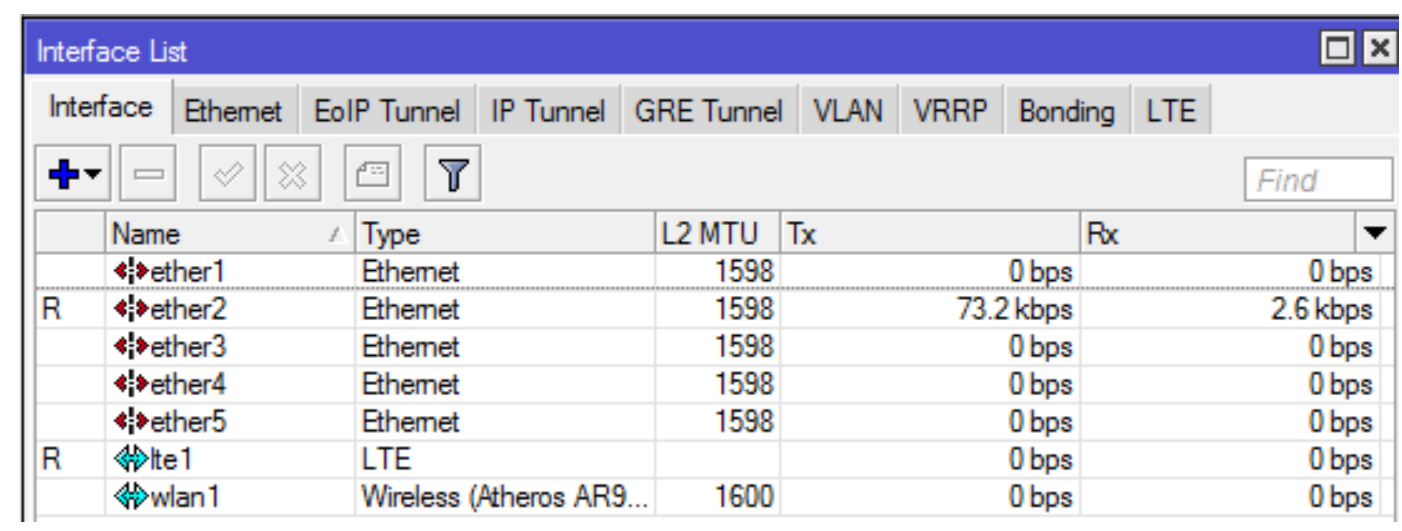

Gambar 10 Interface mikrotik

Pada saat mengaktifkan fitur tethering pada handphone tersebut sudah menyediakan DHCP server dan DNS. Konfigurasi DHCP client pada mikrotik dengan parameter interface yang menuju ke handphone (interface LTE) seperti yang ditunjukkan pada Gambar 11.

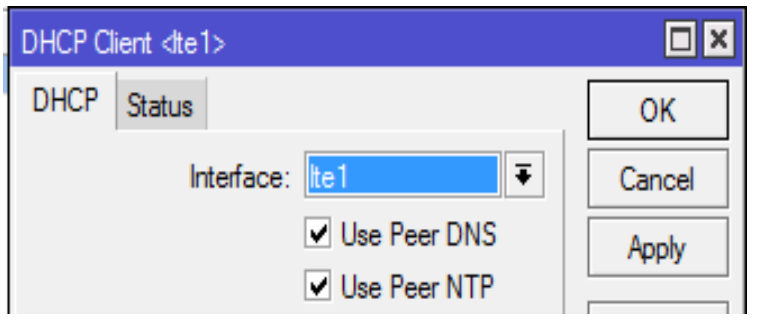

Gambar 2 Konfigurasi DHCP client

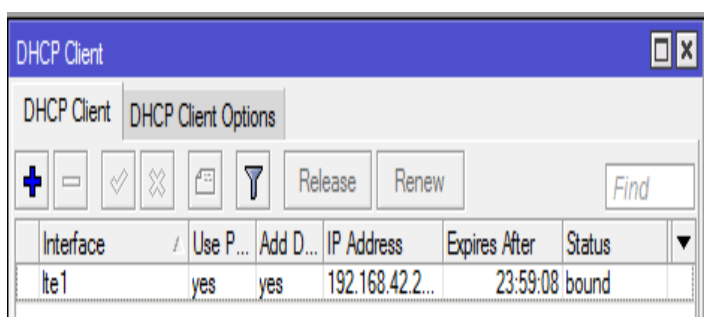

Gambar 3 Status DHCP client

DHCP client pada router akan berubah menjadi status bound ini artinya router berhasil mendapatkan informasi IP Address dari handphone yang ditunjukkan pada Gambar 12.

Konfigurasi yang digunakan hampir sama seperti konfigurasi mikrotik yang bersifat dynamic untuk melakukan konfigurasi DHCP client. Apabila DNS sudah didapatkan mikrotik sudah dapat melakukan akses internet, pengecekan dilakukan dengan melakukan ping ke internet seperti terlihat pada Gambar 13.

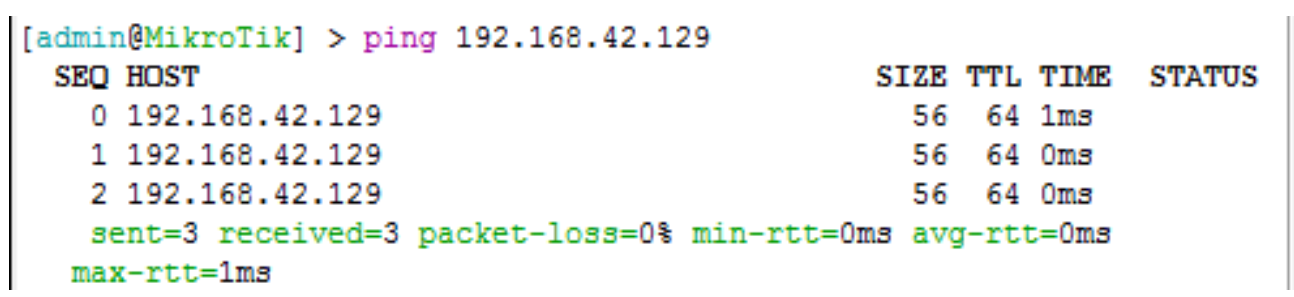

Gambar 4 Pengecekan ping akses internet 
Koneksi access point yang telah dibuat pada router belum didistribusikan pada IP private, hal tersebut karena IP private belum mengenali koneksi masuk yang berasal dari access point. Konfigurasi selanjutnya dapat dilakukan pada bagian firewall agar IP private yang digunakan sebagai client pada pembuatan port knocking dapat terkoneksi dengan internet. Konfigurasi yang dilakukan seperti ditunjukan pada Gambar 14.

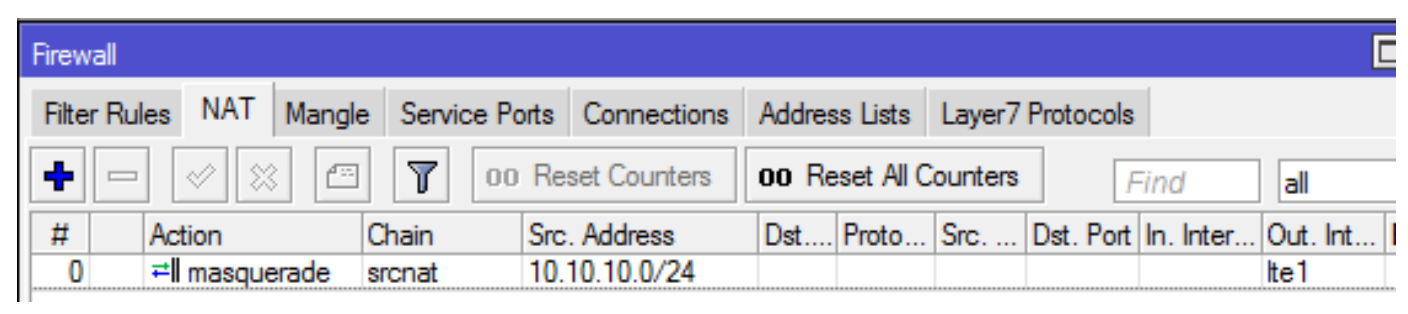

\section{Gambar 5 Konfigurasi NAT}

Konfigurasi utama dalam pembuatan port knocking dengan notifikasi email adalah konfigurasi firewall filter rule, memasukan akun email dan pembuatan scheduler pada mikrotik. Pada konfigurasi ini, firewall filter rule digunakan untuk pembuatan rule log. Log adalah suatu fitur mikrotik untuk menambahkan segala informasi ataupun paket data yang masuk maupun keluar ke log. Penggunaan log berfungsi sebagai pencatat setiap kejadian dalam router. Pembuatan port knocking dengan notifikasi email menggunakan fitur log sebagai media pencatat yang dilakukan client untuk membuka port yang telah ditutup. Pembuatan log menggunakan satu kata kunci yang dapat dikenali untuk setiap port dan disamakan dengan pembuatan scheduler, agar scheduler menangkap perintah yang keluar pada log dengan kata kunci yang sama. Penambah konfigurasi log pada firewall filter rule ditunjukan pada Gambar 15.

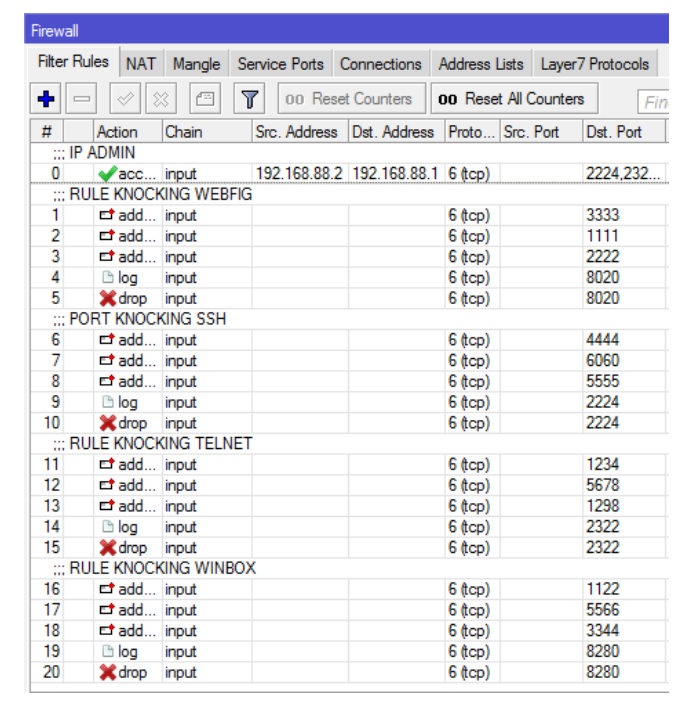

Gambar 6 Penambahan konfigurasi log

Proses pembuatan konfigurasi log terlebih dahulu melakukan penambahan konfigurasi pada port pemicu ketiga yang telah dibuat sebelumnya. Pada port pemicu ketiga akan diaktifkan log dengan nama "ALERT_WEBFIG" hal ini dilakukan agar ketika client berhasil masuk ke port pemicu ketiga akan langsung tercatat dalam log. Konfigurasi ditunjukan pada Gambar 16. 


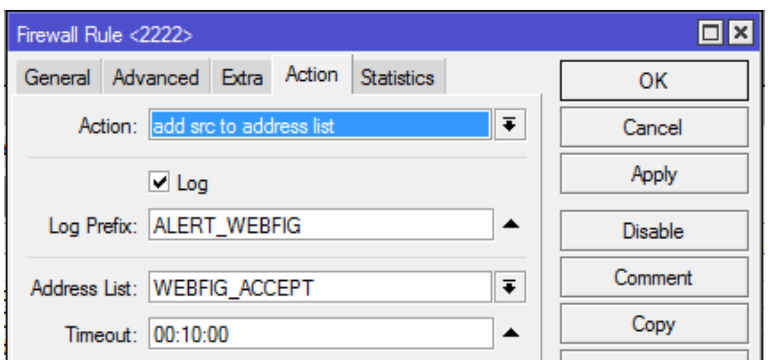

Gambar 7 Penambahan log pada port pemicu ketiga

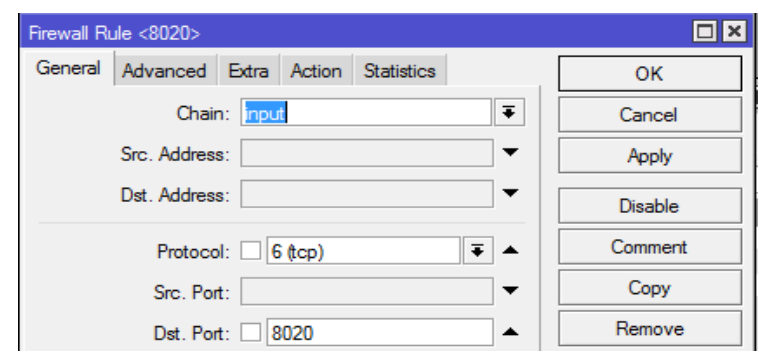

Gambar 8 Pembuatan log pertama

Konfigurasi log selanjutnya pada pembuatan firewall filter rule dengan action log untuk salah satu contoh port mikrotik yaitu port webfig. Konfigurasi dilakukan dengan memasukkan "chain input" yang artinya menangani setiap paket yang masuk ke router atau menuju router berupa protokol tcp dengan port tujuan yaitu port baru dari webfig 8020. Konfigurasi tersebut ditunjukan pada Gambar 17.

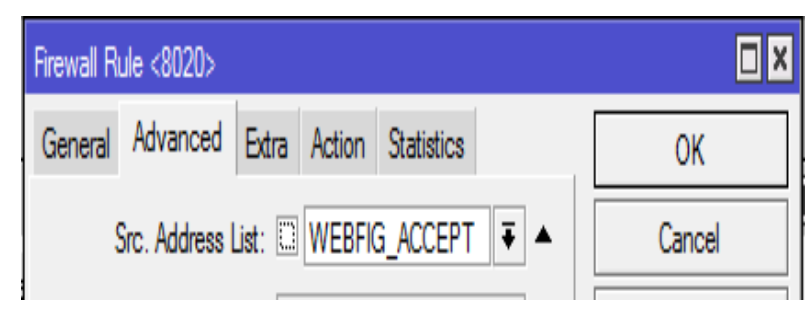

Gambar 9 Pembuatan log kedua

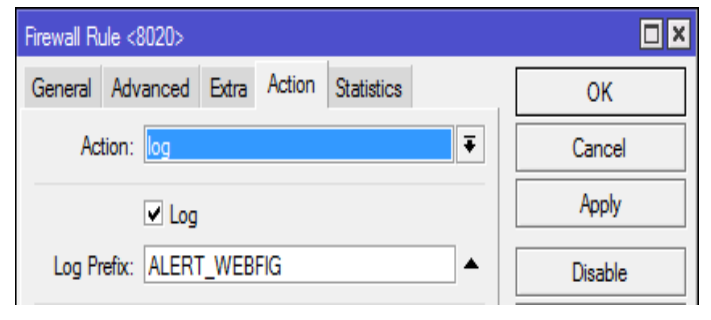

Gambar 10 Pembuatan log terakhir

Gambar 18 menunjukan bahwa paket yang masuk pada router seperti pembuatan log pertama bisa dilakukan apabila sumbernya sudah tercatat sebelumnya pada "address list" yang diberi nama WEBFIG_ACCEPT ini merupakan penamaan address list pada port pemicu ketiga. Hal ini berarti log akan tercatat apabila sumber alamat telah melakukan knocking sampai pada port pemicu ketiga. Sedangkan Gambar 19 menunjukan perintah atau tindakan yang dilakukan selanjutnya dengan perintah log yang diberi nama ALERT_WEBFIG. Perintah tersebut menjadi perintah terakhir dalam pembuatan log dan setiap masukan yang dibuat dapat tercatat pada log.

Pembuatan port knocking dengan notifikasi email dapat berjalan dengan memasukan data-data yang dibutuhkan /tool email pada fitur mikrotik. Hal ini bertujuan agar mikrotik dapat mengirim email dengan meminjam akun email yang telah ada. IP server yang digunakan berasal dari alamat SMTP server gmail dan port gmail. Konfigurasi lebih lengkap ditunjukan pada Gambar 20.

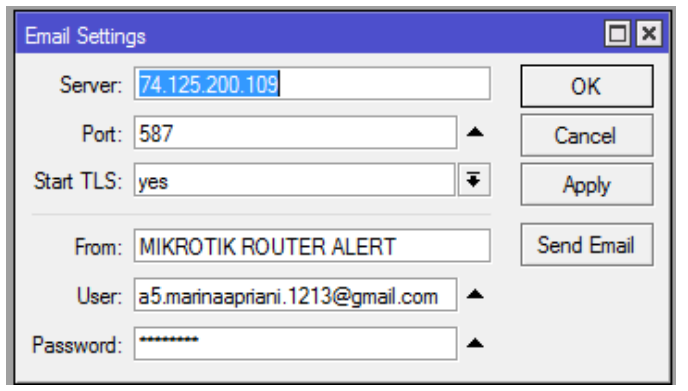

Gambar 11 Konfigurasi email mikrotik

\begin{tabular}{|c|c|c|c|c|c|c|}
\hline Scheduler & & & & & & $x$ \\
\hline 中 & 国 & & & & Find & \\
\hline Name & Stat Date & Stat Time & |nterval & On Event & Owner & $\checkmark$ \\
\hline Alet5SH & Jun/ $/ 04 / 2$ & 7 startup & & D0 local scher & .. admin & \\
\hline AletTennet & Jun/04/2 & 7 statup & & DO local scher & .. admin & \\
\hline AletWebfig & Jun/04/2 & 7 statup & & 00 local scher & ... admin & \\
\hline AletWinbox & Jun/04/2 & 7 startup & & 10 local scher & ... admin & \\
\hline
\end{tabular}

Gambar 12 Baris perintah script scheduler 


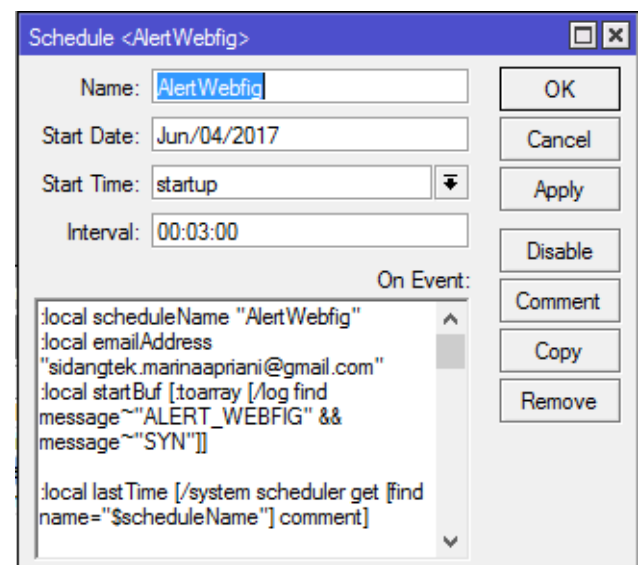

Gambar 13 Pembuatan schedule mikrotik

Gambar 21 menunjukan baris perintah dari masing-masing port mikrotik yang telah dipasang port knocking. Sedangkan Gambar 22 menunjukan pembuatan schedule lebih lengkap dengan salah satu port mikrotik yaitu port webfig. Pada pembuatan schedule menggunakan email yang berbeda pada tool box "on event" dengan konfigurasi email sebelumnya dikarenakan fungsi email yang satu hanya sebagai peminjam akun untuk mikrotik agar dapat mengirimkan email ke alamat email lain. Namun email kedua sebagai penerima pesan masuk berupa notifikasi jika client berhasil masuk pada port mikrotik. Pembuatan schedule bertujuan untuk menangkap log yang tercatat dengan nama ALERT_WEBFIG dan mengirimkan email ke administrator untuk mengetahui bahwa port pada mikrotik telah diketahui.

\section{Fase Pengujian}

Pengujian dilakukan untuk mengetahui keberhasilan notifikasi email, sehingga port knocking dengan notifikasi email dapat dikatakan berhasil apabila email dapat masuk ketika client sudah melakukan knocking pada port mikrotik. Pengujian menggunakan browser dan membuka layanan gmail yang telah dibuat. Pada pengujian ini mengambil salah satu port mikrotik yaitu port webfig.

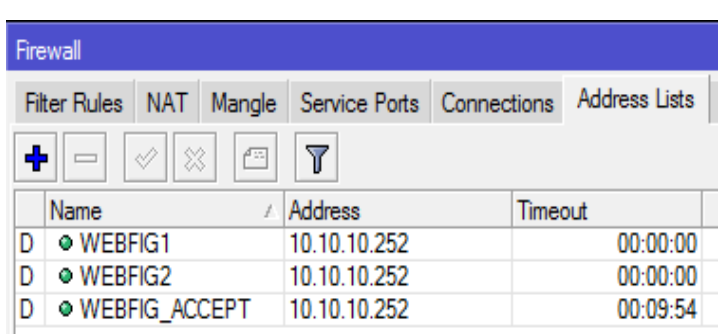

Gambar 14 IP tercatat masuk port webfig

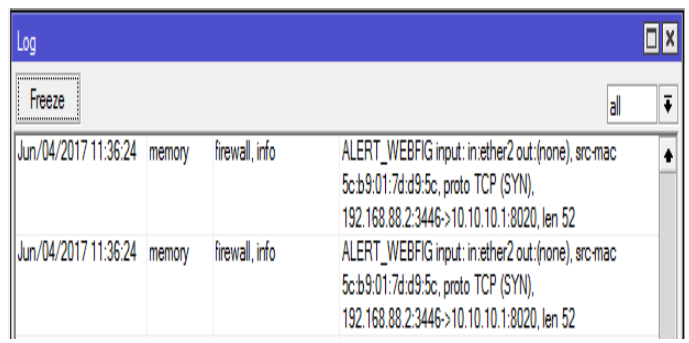

Gambar 15 Serangan tercatat pada log

Gambar 23 menunjukan bahwa client mencoba membuka port pemicu pertama, kedua dan ketiga untuk selanjutnya masuk ke port webfig yang telah dialihkan. Pada saat client berhasil masuk ke port webfig yang telah dialihkan perintah log pun mulai tercatat. Perintah log yang tercatat ditunjukan pada Gambar 24.

Selang waktu beberapa menit administrator jaringan akan mendapatkan pesan masuk berupa email peringatan bahwa port-port pemicu telah berhasil dibuka oleh client hingga port pemicu terakhir. Hal 
ini membuat administrator dapat segera merubah port pemicu agar client tidak dapat membuka port yang telah dibuka. Pesan masuk berupa notifikasi email ditunjukan pada Gambar 25.

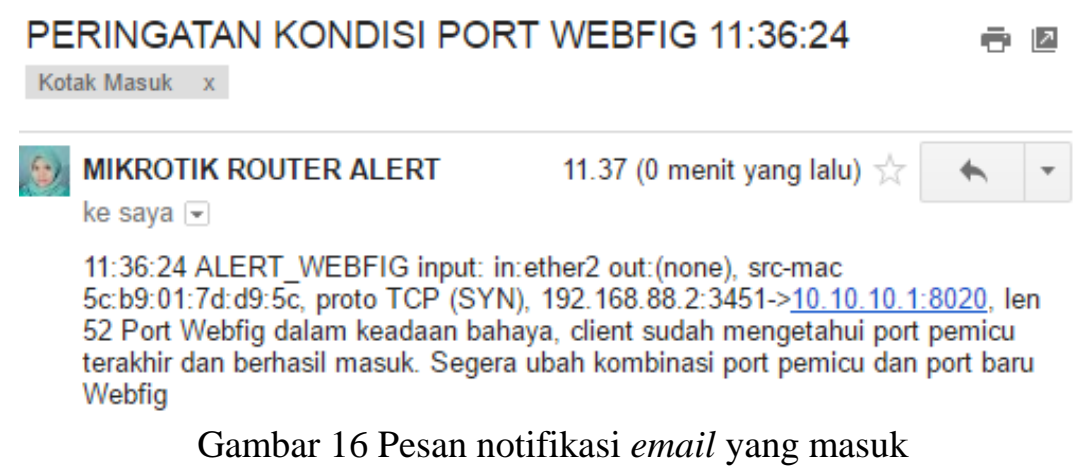

\section{SIMPULAN DAN SARAN}

Setelah dilakukan keamanan port pada mikrotik dengan metode port knocking, dapat dipastikan mikrotik telah memiliki keamanan yang dapat membatasi penggunaan remote access menuju mikrotik dapat dibatasi. Sehingga client yang tidak mempunyai hak akses tidak dapat membuka mikrotik.

Simpulan yang dapat diambil adalah keamanan port menggunakan metode port knocking dengan notifikasi email telah berhasil dilakukan. Serta notifikasi email sudah bisa diterapkan dan sudah berjalan dengan fungsinya. Sehingga administrator mudah memantau router tanpa datang ke tempat router diletakkan dengan pesan notifikasi email yang masuk.

Saran yang dapat diberikan untuk penelitian selanjutnya diintegrasikan notifikasi dengan metode API dan protokol SMTP.

\section{DAFTAR RUJUKAN}

Athailah. 2013. Mikrotik untuk Pemula. Jakarta(ID): Mediakita.

Azwir A. 2014. Mikrotik Firewall : Securing your Router with Port Knocking [Internet]. [diunduh pada 2017 April 02]. Tersedia pada https://www.slideshare.net/akbarazwir/portknock

Towidjojo R. 2015. Mikrotik Kung Fu: Kitab 1 Edisi 2015. Palu(ID):Jasakom.

Nurika O. 2012. Review of various firewall deployment models.

Purnama W. 2014. Analisis dan Perancangan Sistem Pengamanan Akses Otentikasi Menggunakan Metode Port Knocking dan Firewall Action Tarpit pada Mikrotik RB951-2N [Internet]. [diunduh pada 2017 Februari 04]. Tersedia pada http://repository.amikom.ac.id/files/Publikasi 11.11.4693.pdf

Frehner C. 2008. Email, SMS, MMS : The linguistic Creativity of asynchronous Discourse in the new media age. Halaman 37

Krzywinski M. 2003. Port Knocking: Network Authentication Across Closed Ports. SysAdmin Magazine 12: 12-17. 